\title{
System-Dynamic Modeling of the Development of Universities in the Conditions of Informatization
}

\author{
S.N. Lapshina ${ }^{1, \text { a) }}$, E.M. Murzahanova ${ }^{1, b)}$, M.A. Medvedeva ${ }^{1, c)}$, \\ A.V. Prisyazhniy ${ }^{1, \text { d) }}$ A.O. Kolomytseva ${ }^{2, \text { e) }}$ \\ ${ }^{1}$ Ural Federal University, Mira 19, Ekaterinburg, Russia, 620002 \\ ${ }^{2}$ Department of Economic Cybernetics, Donetsk National Technical University, Artema Street 131, Ukraine, 83015 \\ a)s.n.lapshina@urfu.ru \\ b)e.m.babenkova@urfu.ru \\ c)Corresponding author: marmed55@yandex.ru \\ d)praw2003@gmail.com \\ e)anniris21@rambler.ru
}

\begin{abstract}
The work is devoted to the selection of key performance indicators (KPI) of universities, as well as the development of the concept of using these indicators in assessing the effectiveness of universities in the scientific and innovative sector of Russia. The study used a combination of descriptive and deductive methods, as well as experiment. There were analyzed the data on financing, the number of publications indexed in the Web of Science, as well as the number of employees of 14 Russian universities that have been participating since 2013 in the state program "Project 5100". This program is aimed at the adaptation of Russian universities to international standards and incorporating them into international education environment. A system-dynamic model is constructed that allows, on the basis of the key performance indicators, to find new approaches and ways to achieve the goals set and to build an effective university development strategy in the transition to a digital economy.
\end{abstract}

Keywords: key performance indicators; University research potential, system-dynamic model.

\section{INTRODUCTION}

Currently, various ratings are used in the world for a comparative assessment of the effectiveness of universities, both in the preparation of students and in university research. The most common are the following ratings (Times Higher Education, QS World University Rankings, U.S. News, Academic Ranking of World Universities of Shanghai Ranking Consultancy). In compiling these ratings, various approaches are used in terms of the set and number of indicators considered, as well as how to organize and group them. These ratings were designed to evaluate and compare foreign universities, and cannot always be directly used for Russian universities, which are not yet fully included in the international market for education and research and are characterized by certain features.

The main goal of this work is to determine key performance indicators (KPI), and also to offer a conceptual basis for assessing the effectiveness of universities in accordance with KPI, and on this basis to create a system-dynamic model of interaction between Russian universities in the field of scientific activity in order to increase their international rankings.

\section{THEORETICAL BACKGROUND AND HYPOTHESES}

Key Performance Indicators are defined by integrated goals in world universities. They are so important that in literature they are considered as the most important in improving quality and achieving goals.

International Conference of Numerical Analysis and Applied Mathematics ICNAAM 2019

AIP Conf. Proc. 2293, 120025-1-120025-4; https://doi.org/10.1063/5.0027267

Published by AIP Publishing. 978-0-7354-4025-8/\$30.00 
There are many studies on the role of key performance indicators, notably: Hubert (1984) postulated that "without a common understanding of past events, there will be no continuous change and improvement." Therefore, without an assessment of efficiency on the basis of key factors and indicators, there will be no continuous changes and improvements in the quality of universities. Fixel (2002) argues that in order to select key indicators in the first phase, it is necessary to take into account the needs of the organization, then the key indicators and goals will be stabilized and recognized. Finally, they are used in a convenient performance assessment model. The competitive environment in the international arena creates conditions and incentives for the development of universities. As Robinson (2005) and James (2005) stated, the "financial affairs" factor is a very significant factor in assessing the performance of universities. Another key factor for development is youth participation and capacity-building within a single university system $[1,2]$.

Key performance indicators are a guide to decision-making at universities.

The main function of key indicators, in our opinion, is to determine the functionality of the university and its dependence on human capital, as well as their impact on changes and improvements in the field of training the personnel reserve and increasing potential in the key areas of the university activity (Fig. 1).

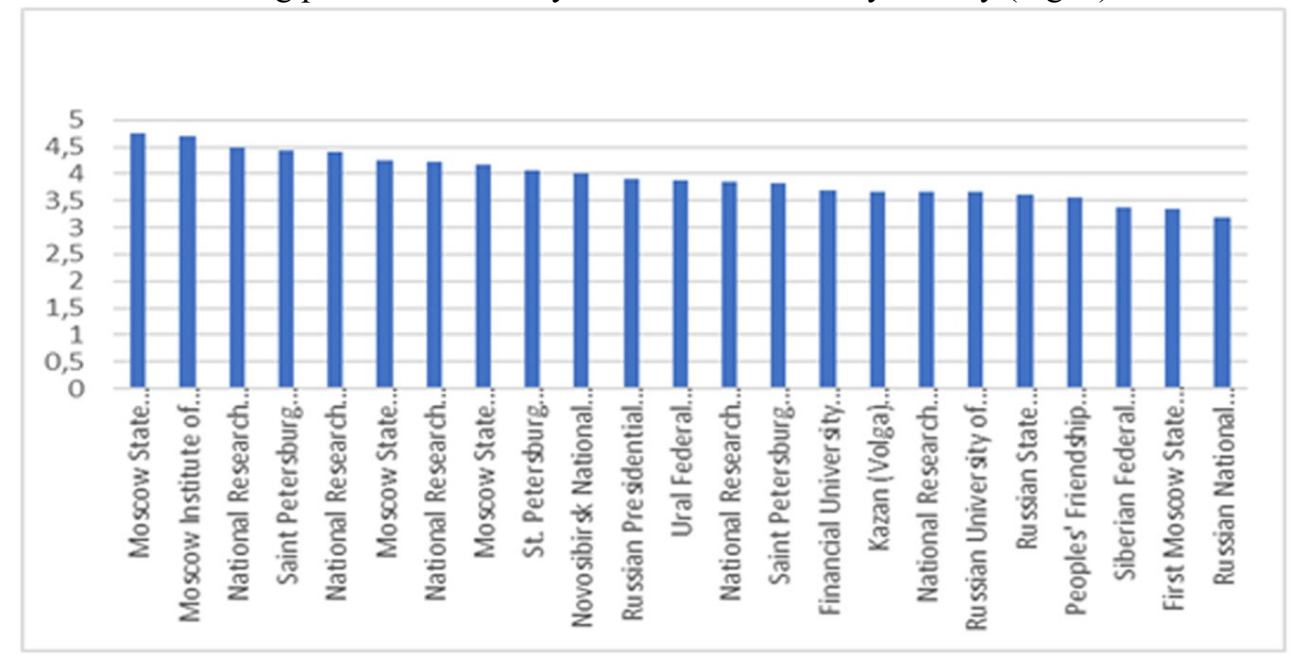

FIGURE 1. Functional rating of some Russian universities.

Figure 1 shows that the level of the functionality of major Russian universities is not very different from each other. Therefore, the question arises of what influences the formation of the main indicators of the rating and the calculation of the total indicator of the effectiveness of research and recognition of Russian universities at the international level. Obviously, these are researchers, faculty, university students and other employees, which can be named as a human capital of the university.

\section{THE METHOD AND THE EMPIRICAL RESULTS}

To create a model of the university's activity, we used a classification model for competitive strategies of agents' behavior in a market with limited resources, which is presented in the form of a triangular diagram (Fig. 3). The mathematical formulation of the problem is based on the model of agent's functioning like "income - costs" and is reduced to solving a system of $\mathrm{N}(\mathrm{t})$ differential equations (Fig. 2). The closure of the system is ensured by the condition of conservation of the resource.

The solution of the system of differential equations is replaced by numerical calculation in the environment of cellular automata $[3,4]$. The capabilities of the cellular automata as a computing environment allow the evolution of complex dynamic systems with a large number of elements nonlinearly interacting with each other to be realized. The development trajectory of the system as a whole substantially depends on the amount of resources, the duration of the destructive periods, and other parameters. 


$$
\begin{aligned}
& d A_{1} / d t=\mathrm{fp}_{1}\left(A_{1}(\mathrm{t}), A \mathrm{Str},(\mathrm{t}), \mathrm{t}\right)-\mathrm{fr}_{1}\left(\mathrm{fp}_{1}(\mathrm{t}), \mathrm{WW}(\mathrm{t}), \mathrm{A}_{1}(\mathrm{t}), \mathrm{AStr}_{1}(\mathrm{t}), \mathrm{t}\right)-\mathrm{fm}_{1}\left(A_{1}(\mathrm{t}), A \mathrm{Str} \mathrm{t}_{1}(\mathrm{t}), \mathrm{t}\right)
\end{aligned}
$$

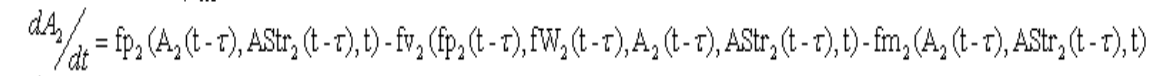

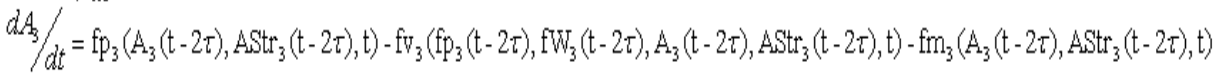

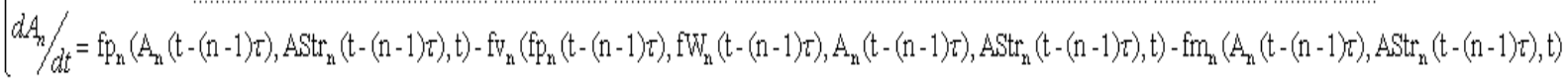

FIGURE 2. The model of agent's functioning as a system of $N(t)$ differential equations.

The work considers the simplest model of cellular automata (CA-model), which step-by-step imitates the growth of an agent, while consuming a resource, which is described by the balance equation:

$$
f_{W}=\frac{d A}{d t}+f_{C}+f_{V}
$$

where:

$f_{W}$ - an input resource stream to the agent, $d A / d t$ - the change in agent assets per unit time,

$f_{C}+f_{V}$ - the flows of fixed and variable costs of the agent, respectively.

Revenues, that is, input streams of a resource, are formed from various sources, such as the university's own funds, state subsidies for educational activities, grants and implemented research projects. It is necessary to determine what type of income and how it is most appropriate to use it to obtain the best result for the university. That is, what goals to set and which proportion of total funds to use for their reaching, in order to raise the rating of the university as a whole.

As a basis for the model constructing, there were used the data on distribution of financial resources from various sources among the functional departments of the university (institutes). These funds are used to finance both educational and research activities that form the main indicators for assessing the performance of individual departments and institutes, and the university as a whole.

Clearly significant factors are the peculiarities of the management system and managers when deciding the resource allocation, speed of adaptation, adoption of any result as experience of further actions and conclusions. These factors are not so obvious at first glance, but they are very important for producing results. The authority and planning horizons of the management are more significant, in our opinion, than the factor of financial support. This is clearly evident on the example of a decrease in the level of funding from the State of the participants of the "5-100 Program" and a further increase of these universities efficiency [5]. In such a situation, it is the established and improved system of management and decision-making that leads to the growth of the university.

The need to support scientific projects of Russian universities and to keep leading world-class scientists in their teams, the creation of an environment conducive to the development of students, the development of universitys' informatization are also significant factors for achieving the goals. A change in these factors with a change in the funding volume allows creating a system-dynamic simulation model $[6,7]$ and using it to build a university strategy based on new approaches and ways to achieve the desired goals in the transition to a digital economy.

Based on the data obtained, we found 151 indicators and 3 conceptual bases (Fig. 3). Key factors include the following: publication of scientific articles in international scientific journals, organizational processes, social and cultural services, the quantity of teaching staff, students, and other university staff. The second structure was also developed with the factors including: "alumni, social and cultural services, periodicals and journals, staff, financial issues and processes connected with students and faculty". 


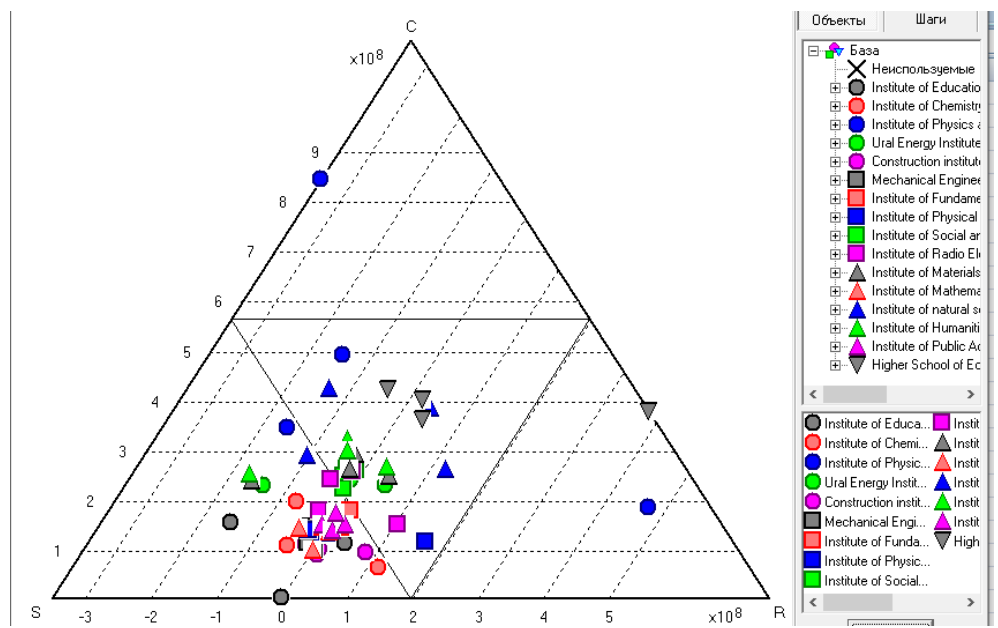

FIGURE 3. System-dynamic model of UrFU development map.

\section{CONCLUSION}

The analysis of modeling data shows that the most important factor for ensuring the growth of performance indicators of Russian universities is the presence of scientists who conduct research and participate in joint projects and exchange experiences with other universities, which ensures the growth of publication activity and citation. The creation and development of effective research teams at universities can be stimulated by targeted state funding, which should be redistributed depending on the performance indicators of universities. Public funds should ensure the competitiveness of leading universities both domestically and on the international market for scientific and educational services.

The effectiveness of the use of earmarked funds at the university can be simulated using the proposed model, in order to provide priority funding for those units whose activities will lead to an increase not only in their own effectiveness, but also to increase the overal university's rating.

\section{REFERENCES}

[1] Alexandr A. Tarasyev, Gavriil Agarkov, Aleksandr Medvedev, "Optimization of Educational Paths for Higher Education", AIP Conference Proceedings 1906, 070008 (2017).

[2] E.G. Chepurov, D.B. Berg, O.M. Zvereva, Yu.Yu. Nazarova, I.V.Chekmarev, "Social Capital Calculations in Economic Systems: Experimental Study", AIP Conference Proceedings 1906, 070015 (2017).

[3] D.B. Berg, K.A. Beklemishev, A.N. Medvedev, and M.A. Medvedeva, "Modeling of the competition life cycle using the software complex of cellular automata PyCAlab", AIP Conference Proceedings 1690, 030003 (2015).

[4] Dmitry B. Berg, Semen V. Gubarev, Alexander N. Medvedev, Ayapbergen A. Taubayev, "Calculations of Wind Mass Transfer of Pollution: Simulation and Analytical Models", IFAC-PapersOnLine, Volume 48, Issue 25, 2015, pp. 227-230.

[5] Ivanov V.V., Markusova V.A., Mindeli L.E., "Government Investments and the Publishing Activity of Higher Educational Institutions: Bibliometric Analysis", Herald of the Russian Academy of Sciences, Vol. 86, No. 4, pp. 314-321 (2016).

[6] E.A. Iskra, A.N. Medvedev, A.V. Brodskaya, N.A. Medvedev, "On the Identification of Threats to Information Security Using the Method of Systemic Dynamics", AIP Conference Proceedings 2116, 200026 (2019).

[7] Anna Kolomytseva, Helen Iskra, Marina Medvedeva, Juliya Glumova, "Imitation Modeling of Commodity Flows in a Logistic Distribution System", AIP Conference Proceedings 2116, 200030 (2019). 